University of Nebraska - Lincoln

DigitalCommons@University of Nebraska - Lincoln

\title{
Antioxidant Activities of Purple Rice Bran Extract and Its Effect on the Quality of Low NaCl, Phosphate-free Patties Made from Channel Catfish (Ictalurus punctatus) Belly Flap Meat
}

\author{
Byungrok Min \\ USDA, Agricultural Research Service \\ Ming $\mathrm{H}$. Chen \\ USDA, Agricultural Research Service \\ Bartholomew W. Green \\ USDA, Agricultural Research Service, bart.green@usda.gov
}

Follow this and additional works at: https://digitalcommons.unl.edu/usdaarsfacpub

Part of the Agriculture Commons, and the Aquaculture and Fisheries Commons

Min, Byungrok; Chen, Ming H.; and Green, Bartholomew W., "Antioxidant Activities of Purple Rice Bran Extract and Its Effect on the Quality of Low $\mathrm{NaCl}$, Phosphate-free Patties Made from Channel Catfish (Ictalurus punctatus) Belly Flap Meat" (2009). Publications from USDA-ARS / UNL Faculty. 2475.

https://digitalcommons.unl.edu/usdaarsfacpub/2475

This Article is brought to you for free and open access by the U.S. Department of Agriculture: Agricultural Research Service, Lincoln, Nebraska at DigitalCommons@University of Nebraska - Lincoln. It has been accepted for inclusion in Publications from USDA-ARS / UNL Faculty by an authorized administrator of DigitalCommons@University of Nebraska - Lincoln. 


\title{
Antioxidant Activities of Purple Rice Bran Extract and Its Effect on the Quality of Low-NaCl, Phosphate-Free Patties Made from Channel Catfish (Ictalurus punctatus) Belly Flap Meat
}

\author{
B. Min, M.-H. ChEN, AND B.W. GreEN
}

\begin{abstract}
Purple rice bran contains high amounts of natural antioxidants that consist of water-and lipid-soluble compounds. Hexane-insoluble and hexane-soluble fractions were separated from $100 \%$ methanolic extract from purple rice bran (RBE-HI and RBE-HS, respectively). Total anthocyanin, tannin, flavonoid, and phenolics contents were determined in those fractions, and their antioxidant capacities were evaluated by measuring 1,1-diphenyl-2picrylhydrazyl (DPPH) radical scavenging capability, oxygen radical absorbance capacity (ORAC), and iron chelating capability (ICC). RBE-HI and RBE-HS were also added to restructured patties made from minced channel catfish (Ictalurus punctatus) belly flap meat. Lipid oxidation, color, and/or textural properties were determined for raw and cooked patties during a 12-d storage at $4{ }^{\circ} \mathrm{C}$. All antioxidant indices, except for ICC, of RBE-HI were significantly higher than those of RBE-HS due probably to its higher anthocyanin content $(P<0.05)$. RBE-HS showed higher ICC $(P<0.05)$. However, both fractions showed similar antioxidant activity in raw and cooked patties during storage, resulting from the complexity of antioxidant action in food systems. Textural properties (hardness, cohesiveness, chewiness, and springiness) in cooked patties with RBE-HS and RBE-HI were well maintained during storage, but changed significantly in the control $(P<0.05)$. Only RBE-HS limited microbial growth in raw patties during storage $(P<0.05)$, but its inhibitory effect was marginal because of low-dose and physical interactions with the matrix. $L^{*}$ (lightness) and $a^{*}$ (redness) of raw and cooked patties decreased significantly by both fractions, whereas $b^{*}$ (yellowness) was significantly decreased by RBE-HI and increased by RBE-HS $(P<0.05)$. In conclusion, we suggest that purple rice bran extract is applicable to meat products as a natural preservative, but color change in the products may limit its application.

Keywords: antimicrobial activity, antioxidant activity, channel catfish belly flap meat, purple rice bran extract, textural properties
\end{abstract}

\section{Introduction}

$\mathrm{L}$ ipid oxidation is a major cause of quality deterioration, such $\longrightarrow$ as development of rancidity and off-flavor, textural degradation, discoloration, and so on, in meat products during storage, rendering them unfit for human consumption (Kanner 1994; Morrissey and others 1998). In addition, the failing of the regulatory systems for reactive oxygen species (ROS) in meat during postmortem processing increases the amount of ROS and lipid oxidation secondary products, such as aldehydes, ketones, and hydrocarbons, whose potential relationship to the incidence of most chronic diseases such as cardiovascular diseases, diabetes, cancer, brain injury, and so on, is well recognized (Ames and others 1995; Halliwell and Gutteridge 1999). Therefore, various synthetic antioxidants, such as butylated hydroxytoluene (BHT), are widely used in the meat industry to ensure product preservation and shelf life extension as well as to minimize risks to consumers' health from

MS 20080748 Submitted 9/25/2008, Accepted 1/26/2009. Authors Min and Chen are with U.S. Dept. of Agriculture, Agricultural Research Service, Rice Research Unit, 1509 Aggie Dr., Beaumont, TX 77713, U.S.A. Author Green is with U.S. Dept. of Agriculture, Agricultural Research Service, Stuttgart National Aquaculture Research Center, 2955 HWY 130E, Stuttgart, AR 72160, U.S.A. Direct inquiries to author Green (E-mail: bart.green@ars.usda.gov).

Mention of trade names or commercial products in this publication is solely for the purpose of providing specific information and does not imply recommendation or endorsement by the U.S. Dept. of Agriculture.
ROS and lipid-oxidation secondary products. However, recent increases in consumers' awareness of health benefits from natural products and concerns about use of synthetic antioxidants have led the meat industry to consider substituting natural plant extracts for synthetic preservatives.

Natural extracts from various plant sources, such as herbs, spices, vegetables, fruits, and grains, possess strong antioxidant activities and can provide various human health benefits (Block and others 1992; Jacobs and others 1995; Ness and Powles 1997; Balasundram and others 2006; Kar and others 2006). The antioxidant activities of the plant natural extracts are mainly attributed to the presence of various phenolic compounds and may be enhanced by their synergistic interactions. Phenolic compounds can be multifunctional and act as free radical scavengers to terminate free radical chain reactions, as reducing agents to recover antioxidant radicals, and/or as metal ion chelators to keep metal ion such as ionic iron from catalyzing the initiation of free radical chain reactions (Shahidi and Wanasundara 1992). It is reported that the plant natural extracts from grape seed, green tea, and rosemary effectively retard development of processing-related lipid oxidation in meat products (Han and Rhee 2005; Rojas and Brewer 2007; Ahn and others 2007). In addition, some extracts from rosemary, sage, oregano, and tea are reported to possess antimicrobial activity against foodborne pathogens (Hammer and others 1999; Elgayyar 
and others 2001; Ahn and others 2007; Bozin and others 2007). Rosemary extract, which is available commercially in the United States and Europe, is extensively investigated for use at $0.02 \%$ to $1 \%$ in various meat products to prevent lipid oxidation and microbial growth (Nissen and others 2004; Fernández-López and others 2005; Sebranek and others 2005; Ahn and others 2007).

Rice bran, a byproduct of rice milling, is a constituent (approximately $10 \%$ ) of the whole rice grain and consists of the bran layers (pericarp, seed coat, nucellus, and aleurone) and the germ (Rohrer and Siebenmorgen 2004). The typical color of rice bran is light brown. Rice bran is the most nutritious part of rice grain and a rich source of bioactive phytochemicals. Rice bran shows strong antioxidant activities in various food systems (Nanua and others 2000; Kim and Godber 2001) and health beneficial effects, such as reduced total plasma cholesterol, increased HDL cholesterol level, and inhibited platelet aggregation (Gerhardt and Gallo 1998; Bramley and others 2000; Cicero and Gaddi 2001; Jariwalla 2001). The high antioxidant capacity of light brown rice bran is mainly attributed to its lipophilic antioxidants, which include $\gamma-$ oryzanol, tocopherols, and tocotrienols (Quereshi and others 1997; Cicero and Gaddi 2001; Wu and others 2004). These lipid-soluble antioxidants consist of a phenolic compound with hydroxyl groups, which are responsible for antioxidant activity and a hydrocarbon side chain or phytosterol, which provides these compounds with hydrophobic characteristics. Wu and others (2004) indicate that the antioxidant capacity measured by oxygen radical absorbance capacity (ORAC) value in lipophilic fraction of the rice bran is significantly greater than that in its hydrophilic fraction.

Unlike the light brown rice bran, red and purple-pigmented rice bran contains high amounts of hydrophilic phenolic compounds such as anthocyanins, in addition to the lipophilic antioxidants (Hu and others 2003). Ling and others (2001) report that the development of ROS in liver, lipid oxidation in aorta, and the area of atherosclerotic plaque is lower in rabbits fed with red and purple bran rice, compared to those fed with light colored bran. Goffman and Bergman (2004) report that the concentration of total phenolic contents in red and purple rice bran is approximately 10 times higher than in light brown rice bran, indicating that the antioxidant activity of rice bran is closely related to rice bran color. Anthocyanins, a member of classes of flavonoids, are responsible for the color of purple rice bran. Major components of anthocyanins in black rice with purple bran are cyaniding-3-glucoside and peonidin-3-glucoside and are mainly located in the aleurone layer of the rice bran ( $\mathrm{Hu}$ and others 2003). Anthocyanins are reported to possess remarkable antioxidant activities (Satue-Gracia and others 1997; Nam and others 2006; Philpott and others 2006) as well as anti-inflammatory properties (Hu and others 2003). Therefore, these findings suggest that compared to light-brown rice bran, purple rice bran may be a well-balanced source of both hydrophilic and lipophilic antioxidants for foods like meat products, which are complex mixtures of hydrophilic and lipophilic components. In addition, inclusion of natural extracts can provide the healthbeneficial phytonutrients to the meat products.

We developed low $\mathrm{NaCl}$ (1\%), phosphate-free restructured patties made from minced channel catfish (I. punctatus) belly flap meat using microbial transglutaminase and isolated soy protein (Min and Green 2008). A product of catfish fillet processing, belly flap meat is a low-valued meat with high fat content. Its high fat content is responsible for its limited shelf life and undesirable flavor and texture qualities in this further processed product. Thus, the inclusion of antioxidants would retard lipid oxidation in processed products, extend the shelf life, and maintain sensory quality properties of the patties during storage. The objectives of this study were to determine the phenolic compounds content, including anthocyanins, tannin, flavonoids, and total phenolics, in purple rice bran extract, to evaluate the antioxidant capacities of the purple rice bran extract, including free radical scavenging capacity and metal chelating capability, and to determine the effects of the purple rice bran extract on the development of lipid oxidation, changes in textural properties, and microbial growth in catfish patties during cold storage.

\section{Materials and Methods}

\section{Chemicals and reagents}

Trolox (6-hydroxy-2,5,7,8-tetramethylchromane-2-carboxylic acid), sodium nitrite, aluminum chloride, 2-thiobarbituric acid (TBA), ferrozine (3-[2-pyridyl]-5,6-bis [4-phenyl sulfonic acid]-1,2,4-triazine), ammonium ferrous sulfate, 1,1-diphenyl2-picrylhydrazyl (DPPH), fluorescein disodium (FL), dimethyl sulfoxide (DMSO), $\alpha$-tocopherol, and butylated hydroxytoluene (BHT) were purchased from Sigma-Aldrich (St. Louis, Mo., U.S.A.). Kuromanin, (+)-catechin, and Folin-Ciocalteu reagent were obtained from Fluka (Milwaukee, Wis., U.S.A.). 2,2'-Azobis(2amidinopropane) dihydrochloride (AAPH) was purchased from Wako chemicals (Richmond, Va., U.S.A.). Randomly methylated $\beta$-cyclodextrin (RMCD) was purchased from Cyclodextrin Technologies Development Inc. (Highsprings, Fla., U.S.A.). Methanol and acetone were high-performance liquid chromatography (HPLC) grade from Fisher Scientific (Fair Lawn, N.J., U.S.A.). Hexane was UltimAR grade from Mallinckrodt Baker Inc. (Phillipsburg, N.J., U.S.A.). Rosemary extract (Fortium R10WS; water-soluble type) was obtained from Kemin Food Ingredients Inc. (Des Moines, Iowa, U.S.A.). Microbial transglutaminase (MTGase; Activa ${ }^{\mathbb{R}}$ TI) was obtained from Ajinomoto Food Ingredients (Chicago, Ill., U.S.A.) and isolated soy protein (ISP; Supro ${ }^{\mathbb{B}} 500 \mathrm{E}$ ) from Solae LLC (St. Louis, Mo., U.S.A.). All other chemicals and reagents used were of reagent grade.

\section{Preparation of rice bran extract}

Rice bran extract (RBE) was prepared from a purple bran cultivar IAC600, developed by Dr. Bastos (Instituto Agronômico, Campinas [SP] Brazil). The IAC600 was grown in 2005 at Beaumont (Tex., U.S.A.) using the standard cultural management practices for this region. After removing husks from the rough rice, the resulting brown rice (with bran layers and germ still intact) was stored at $-20^{\circ} \mathrm{C}$ until use. The brown rice was milled using Satake Motor onepass mill (Tokyo, Japan) and the bran fraction, including bran and germ, was sieved through an 840-micron sieve (nr 20, E.H. Sargent \& Co., Chicago, Ill., U.S.A.). The rice bran was extracted with $100 \%$ methanol overnight with shaking at a bran-to-solvent ratio of 1:10 under nitrogen gas at room temperature. The next day, the mixture was centrifuged at $4000 \times g$ for $10 \mathrm{~min}$ at $20^{\circ} \mathrm{C}$, and then the supernatant was collected. The pellet was extracted with $100 \%$ methanol one more time for $2 \mathrm{~h}$. Both supernatants were pooled and filtered through $0.45-\mu \mathrm{m}$ polyvinylidene fluoride (PVDF) membrane (Waters Corp., Milford, Mass., U.S.A.), and then methanol was evaporated under reduced pressure $\left(400\right.$ mTorr at $\left.-130{ }^{\circ} \mathrm{C}\right)$ using cold trap (Titan ${ }^{\mathrm{TM}}$ Vapor Trap, FTS systems Inc., Stone Ridge, N.Y., U.S.A.). The $100 \%$ methanol extract was further separated into two fractions: hexane-soluble (RBE-HS) and hexane-insoluble fractions (RBE-HI). The extract was mixed with an equal volume of hexane by vortexing for $5 \mathrm{~min}$ and sonicating for $2 \mathrm{~min}$, followed by centrifugation at $4000 \times g$ for $10 \mathrm{~min}$ at $20^{\circ} \mathrm{C}$. The hexane extraction was repeated one more time. Hexane layers from both extractions were pooled and then hexane was evaporated 
under the reduced pressure to collect RBE-HS. The lower layer was lyophilized for RBE-HI. Both fractions were flushed with nitrogen gas and stored in freezer until use.

\section{Various indexes for antioxidant activities of rice bran extracts}

Rosemary extract (RE), RBE-HI, and RBE-HS were reconstituted and diluted with acidified ethanol (85\% ethanol and 15\% $1.5 \mathrm{~N}$ $\mathrm{HCl}, \mathrm{v} / \mathrm{v}$ ) to determine total anthocyanin content according to the method of Abdel-Aal and Hucl (1999). Total anthocyanin content was expressed as microgram kuromanin equivalents per milligram sample. Total tannin content was quantified by the vanillin assay of Sun and others (1998), using the reconstituted solution of RBE-HI, RBE-HS, and RE with $100 \%$ methanol and expressed as microgram catechin equivalents per milligram sample.

For total flavonoid content, total phenolic content, DPPH scavenging capability, ORAC values, and iron chelating capability, RBEHI, RBE-HS, and RE were reconstituted with DMSO. Total flavonoid content was determined by the method of Zhishen and others (1999) and expressed as microgram catechin equivalents per milligram sample. Total phenolics content was analyzed by the method of Goffman and Bergman (2004) with modification. Briefly, 0.6 mL of sample or standard was diluted with DMSO appropriately and mixed with $0.25 \mathrm{~mL}$ of $20 \%$ Folin-Ciocalteu reagent. After $5 \mathrm{~min}$, $0.5 \mathrm{~mL}$ of $0.5 \mathrm{M}$ ethanolamine was added to the mixture. After 90 min of color development at room temperature, the absorbance was measured at $760 \mathrm{~nm}$ against the reagent blank. Total phenolic content was expressed as microgram gallic acid equivalents per milligram sample. Methodology of Goffman and Bergman (2004) was used to assay DPPH scavenging capability by monitoring the scavenging activity of DPPH radicals by samples and was calculated by a linear regression equation between a series of concentrations of gallic acid as a standard and their absorbance and was expressed as microgram gallic acid equivalents per milligram sample.

The procedure of Huang and others (2002a, 2002b) with modification was used to determine hydrophilic for RBE-HI and lipophilic ORAC values for RBE-HS and RE. An Infinite 200 microplate reader equipped with Magellan reader software (version 6.4; Tecan, Grödig, Austria) was used with a fluorescence filter for an excitation wavelength of $485 \mathrm{~nm}$ and an emission wavelength of $520 \mathrm{~nm}$. RBE-HI, Trolox as a standard, FL, and AAPH were diluted with or prepared in $75 \mathrm{mM}$ phosphate buffer, $\mathrm{pH} 7$, whereas RBE-HS, $\mathrm{RE}$, and Trolox were diluted with 7\% RMCD in 50\% acetone solution $(\mathrm{w} / \mathrm{v})$. Aliquots of the diluted samples or standards $(50 \mu \mathrm{L})$ were added to a 96-well black polystyrene, flat bottom plate with a lid (Coring, Corning, N.Y., U.S.A.). FL solution (100 $\mu \mathrm{L}$; final conc. $0.048 \mu \mathrm{M}$ ) was added to samples or standards in the 96 -well plate and preincubated at $37^{\circ} \mathrm{C}$ for $15 \mathrm{~min}$ in the microplate reader. After AAPH (50 $\mu \mathrm{L}$; final conc. $63.4 \mathrm{mM}$ ) was rapidly added to each well, the plate was immediately transferred to the plate reader and agitated for $10 \mathrm{~s}$ prior to the first reading and each subsequent reading. Fluorescence was measured at every 2.5-min interval for $60 \mathrm{~min}$ for hydrophilic ORAC and $120 \mathrm{~min}$ for lipophilic ORAC at $37{ }^{\circ} \mathrm{C}$. The ORAC values were calculated using a linear regression equation $(y=a x+b)$ between a series of Trolox concentrations ( $y$; $1.56-12.51 \mu \mathrm{g} / \mathrm{mL}$ ) and the net area under the fluorescence decay curve (net AUC) $(x)$. The area under the curve (AUC) was calculated as:

$\mathrm{AUC}=\left(0.5+f_{2} / f_{1}+f_{3} / f_{1}+f_{4} / f_{1}+\cdots+f i / f_{1} \cdots+f_{24} / f_{1}\right) \times C T$

where $f_{1}=$ the initial fluorescence reading, $f_{i}=$ the fluorescence reading at cycle $i$, and $C T=$ cycle time in minutes.
The net AUC was calculated by subtracting the AUC of blank from the AUC of samples or standards. ORAC value was expressed as microgram Trolox equivalents per milligram sample.

Iron chelating capability was assayed using the ferrozine method (Carter 1971). In brief, $100 \mu \mathrm{L}$ of sample or standard were mixed with $100 \mu \mathrm{L}$ of $1 \mathrm{mM}$ ammonium ferrous sulfate solution and $2.7 \mathrm{~mL} 10 \%$ ammonium acetate buffer solution. After $5 \mathrm{~min}, 50 \mu \mathrm{L}$ of $6.1 \mathrm{mM}$ ferrozine color reagent were added to the mixture and mixed thoroughly. After $10 \mathrm{~min}$, the absorbance was determined at $562 \mathrm{~nm}$. Iron chelating capability was calculated by using a linear regression equation between a series of concentrations of gallic acid as a standard and their absorbance and expressed as microgram gallic acid equivalents per milligram sample.

\section{Production of patties}

Fresh channel catfish belly flap meat was purchased from an Arkansas processor. Upon receipt, the meat was washed using a pressure washer (2200 psi, Troy-Bilt Model 020295, Briggs \& Stratton Power Products Group, LLC, Jefferson, Wis., U.S.A.) for $5 \mathrm{~min}$ to remove excessive fat and de-pigment the adhered peritoneal membrane. The washed meat was drained for around $2 \mathrm{~h}$ in the refrigerator before storing in vacuum-packaging bags $\left(\right.$ Cryovac $\left.^{\circledR}\right)$ HP2700 vacuum bag, Sealed Air, Duncan, S.C., U.S.A.). The vacuum-packaged meat was stored at $-20^{\circ} \mathrm{C}$ until use.

The formulation of ingredients and patty preparation conditions in this study were based on our previous study (Min and Green 2008). Belly flap meat was thawed overnight in a refrigerator and ground separately twice using a grinder (Model 722, Biro Manufacturing Co. Ltd., Marblehead, Ohio, U.S.A.) fitted with a plate with six 18-mm diameter openings. Six treatment groups were prepared with: (1) control (no antioxidant), (2) $0.02 \% \mathrm{BHT}(\mathrm{w} / \mathrm{w})$, (3) $0.1 \% \alpha$-tocopherol $(w / w),(4) 0.1 \%$ rosemary extract (RE) (w/w), (5) $0.1 \%$ RBE-HI (w/w), and (6) $0.1 \%$ RBE-HS (w/w). BHT and $\alpha$ tocopherol were used as references for synthetic and natural antioxidants, respectively, and RE was used as a reference for natural extract. The RBE-HI, RBE-HS, and RE were dissolved in $70 \%$ ethanol $(71 \mathrm{mg} / \mathrm{mL}$ ) and others were dissolved in $100 \%$ ethanol. The ground meat was mixed with sodium chloride (1\%), water $(10 \%)$, and antioxidants for 2 min in a mixer (Model KSM150PSOB, KitchenAid, St. Joseph, Mich., U.S.A.). Ethanol was added to the control and other treatments, if needed, to equalize the ethanol level in every treatment. MTGase-water (1:3, w/w) and ISP-water (1:4, w/w) mixtures were subsequently added to the mince and mixed for $2 \mathrm{~min}$. The final concentration of MTGase and ISP were $0.1 \%$ and $1.7 \%$, respectively. Total mixing time was standardized to $4 \mathrm{~min}$ and the final temperature of the meat mixture in all treatments was kept below $12{ }^{\circ} \mathrm{C}$ throughout the mixing process. Four replicate batches (500 g per batch) were prepared for each treatment. Patties (100 g; 100 -mm diameter) were formed using a hamburger press (Model 1404, Univex, Salem, N.H., U.S.A.) and stored overnight at $4{ }^{\circ} \mathrm{C}$ in the refrigerator for the reaction of MTGase. For the cooked patty study, the same experimental set of patties as previously mentioned was prepared on a different day. Patties were cooked in a superheated steam oven (Model AX700R, Sharp Electronics, Mahwah, N.J., U.S.A.) at $227^{\circ} \mathrm{C}$ to an internal temperature of $80^{\circ} \mathrm{C}$. Raw and cooked patties were individually packaged in oxygen-permeable zipper bags (polyethylene, $4 \times 6$, 2 mil.; Associate Bag Co. Milwaukee, Wis., U.S.A.) and stored at $4{ }^{\circ} \mathrm{C}$ in the refrigerator until used. Raw and cooked patties were analyzed for 2-thiobarbituric acid-reactive substances (TBARS), color values, and textural profile analysis (for only cooked patties) at $0,3,6,9$, and $12 \mathrm{~d}$ of storage. Aerobic plate count (APC), coliform plate count (CPC), and yeast 
plate count (YPC) were determined for only raw patties at $0,2,4,6$, and $8 \mathrm{~d}$ of storage.

\section{2-Thiobarbituric acid reactive substances}

Raw and cooked patties were analyzed for TBARS value, as a lipid oxidation index, according to the method of Min and Ahn (2008). Briefly, $5 \mathrm{~g}$ of ground meat were homogenized with $15 \mathrm{~mL}$ DDW and $100 \mu \mathrm{L}$ BHT solution (6\% in $100 \%$ ethanol, w/v) using a homogenizer (Fisher Scientific, Pittsburgh, Pa., U.S.A.) for $15 \mathrm{~s}$ at speed 7. The meat homogenate $(1 \mathrm{~mL})$ was mixed with $2 \mathrm{~mL}$ TBA/TCA solution (20 mM TBA/15\% trichloroacetic acid [TCA; w/v]). The mixture was incubated for $15 \mathrm{~min}$ in a boiling water bath. After cooling, the mixture was centrifuged at $3000 \times g$ for $15 \mathrm{~min}$. The absorbance of the supernatant was determined at $531 \mathrm{~nm}$ against a reagent blank. The amount of TBARS was expressed as milligrams malondialdehyde (MDA) per kilogram meat.

\section{Color measurement}

Commission Internationale de l'Eclairage (CIE) $L^{*}$ (lightness), $a^{*}$ (redness), and $b^{*}$ (yellowness) for raw and cooked patties during storage were determined using a HunterLab Miniscan XE plus colorimeter (Model 4500L, Hunter Associate Laboratory Inc., Reston, Va., U.S.A.) with $25-\mathrm{mm}$ aperture, CIE D65 illuminant, and $10^{\circ} \mathrm{stan}-$ dard observer. The colorimeter was calibrated against black and white reference tiles. Color values were measured on the surface of 2 patties per each batch and 6 measurements per each patty ( 3 on each side of the patty). Whiteness (Park 2000) was calculated by the following equations:

$$
\text { Whiteness }=100-\left[\left(100-L^{*}\right)^{2}+a^{* 2}+b^{* 2}\right]^{1 / 2}
$$

\section{Texture profile analysis}

An Instron universal testing machine (Model 3342, Instron Co., Norwood, Mass., U.S.A.) equipped with a 500-N load cell was used to analyze texture properties of the cooked patties during storage. Texture profile analysis (TPA) was performed using a $90-\mathrm{mm}$ diameter aluminum plunger according to the methods of Bourne (2002). Two cylindrical samples $(20 \mathrm{~mm}$ in diameter and $18 \mathrm{~mm}$ in thickness) were extracted from each patty and compressed through two repeated cycles with $80 \%$ compression of the initial height at a crosshead speed of $60 \mathrm{~mm} / \mathrm{min}$. There was a 5 -s rest period between the 2 cycles to allow the sample to recover its height. Hardness, cohesiveness, chewiness, and springiness were calculated from the TPA curve. Hardness $(N)$ was defined as the peak force during the first compression cycle, cohesiveness as the ratio of the positive force area under the second (A2) compression to under the first (A1) compression, chewiness $\left(N^{*} \mathrm{~mm}\right)$ as the energy required to compress the sample and the product of hardness $\times$ cohesiveness $\times$ springiness, and springiness (\%) as the ratio of the height recovered during the rest period between the 1st and 2nd cycles to the original height to the sample (Bourne 2002).

\section{Microbiological analysis}

APC, CPC, and YPC were determined for raw patties using Petrifilm ${ }^{\mathrm{TM}}$ aerobic count plate, coliform count plate, and yeast/mold count plate (3M Co., St. Paul, Minn., U.S.A.), respectively. At each storage interval, a 25-g sample of the patties was homogenized with $225 \mathrm{~mL}$ sterile Butterfield's phosphate buffer $(0.3 \mathrm{mM}$ potassium phosphate buffer, $\mathrm{pH} 7.2$; $3 \mathrm{M}$ Co.) for $2 \mathrm{~min}$ at room temperature. Appropriate serial dilutions were made with sterile Butterfield's phosphate buffer, and then $1 \mathrm{~mL}$ of each dilution was spread duplicate on appropriate plates for APC, CPC, and YPC. The plates for APC were incubated at $35^{\circ} \mathrm{C}$ for $48 \mathrm{~h}$, for $\mathrm{CPC}$ at $35^{\circ} \mathrm{C}$ for $24 \mathrm{~h}$, and for YPC at $20^{\circ} \mathrm{C}$ for $5 \mathrm{~d}$ (AOAC 2005).
Data were expressed as $\log _{10}$ colony forming units (CFU) per gram sample.

\section{Statistical analysis}

All data were analyzed by one-way or two-way analysis of variance using the SAS program (version 9.1 for windows, SAS Inst. Inc., Cary, N.C., U.S.A.) and reported as means and standard error of the mean (SEM) in tables and means and standard deviation (SD) in figures. The analyses for all antioxidant indexes for RBE-HI, RBEHS, and RE were performed in triplicate $(n=3)$. In the study using catfish patties, 4 batches for each treatment were produced for TBARS, surface color, and TPA measurements $(n=4)$. For microbiological analysis, 3 batches from each treatment were randomly selected and analyzed $(n=3)$. Student-Newman-Keuls' multiple range test was used to compare the mean values of treatments $(P<$ 0.05) (Kuehl 2000).

\section{Results and Discussion}

\section{Phenolic compounds and antioxidant capacity of purple rice bran extract}

Methanolic extract from purple rice bran was further extracted by hexane, resulting in hexane-insoluble and hexane-soluble fractions (RBE-HI and RBE-HS, respectively) to compare the antioxidant capacities of nonlipophilic and lipophilic components in purple rice bran extract. The lipophilic components such as tocopherols, tocotrienols, and $\gamma$-oryzanol have been well recognized as major antioxidants in typical light brown rice bran extract (Quereshi and others 1997; Cicero and Gaddi 2001). Rosemary extract (RE) was chosen as a reference of natural extract in this study because its antioxidant activity in meat products has been well demonstrated and commercially available in the United States. Carnosol and carnosic acid, phenolic diterpenes, were reported to account for around $90 \%$ of antioxidant capacity in commercially available rosemary extract (Wijeratne and Cuppett 2007).

Total anthocyanin content, total flavonoid content, and total phenolics content in RBE-HI was significantly higher than those in RBE-HS and RE $(P<0.05)$ (Table 1$)$. Anthocyanin appeared to be primarily responsible for total flavonoid and total phenolics contents in RBE-HI. Anthocyanins are one of the most abundant natural colorants in nature and belong to the class of flavonoids. Hu and others (2003) indicated that the major anthocyanins found in black rice, cyanide-3-glucoside, and peonidin-3-glucoside, have strong antioxidant activities in an in vitro model system. Compared to those of RBE-HS and RE, the ORAC value and DPPH scavenging capability of RBE-HI was significantly higher and appeared to be closely related to its higher total anthocyanins, flavonoids, and phenolics contents $(P<0.05)$ (Table 1$)$. Total tannin content was much lower than total flavonoids and total phenolics content in RBE-HI and RBE-HS, but not detected in RE. Tannins were reported to have free-radical scavenging activity (Oki and others 2002). Therefore, tannins in RBE-HI and RBE-HS may be contributing to the DPPH scavenging ability and ORAC values. However, profiles of phenolic compounds present in purple rice bran have not been fully investigated yet because most studies on the antioxidants in rice bran have focused on its lipophilic compounds. Further studies on the identification of phenolic compounds in purple rice bran are needed.

The iron chelating capability in RBE-HS was significantly higher than that in RBE-HI, but was not detected in RE $(P<0.05)$ (Table 1$)$. The status of free ionic iron is very important for the development of lipid oxidation in meat products because the reactivity of ferric ion is negligible (Ahn and Kim 1998). Free-ionic iron catalyzes 
the production of hydroxyl radical $(\mathrm{OH})$ from $\mathrm{H}_{2} \mathrm{O}_{2}$ as well as the degradation of lipid hydroperoxides to produce peroxyl and alkoxyl radicals, which can initiate lipid oxidation and/or be self-degraded to the secondary products of lipid oxidation (Min and Ahn 2005). Min and others (2008) reported that the ferric ion reducing capacity to ferrous ion, the reactive form for catalyzing lipid oxidation, was present in cooked meat. Therefore, free ionic iron is regarded as a primary catalyst for lipid oxidation in cooked meat products because other catalysts such as hemoglobin and myoglobin are denatured and degraded to release free ionic iron by heating (Min and Ahn 2005). The chelation of free ionic iron is a promising approach to retard the development of lipid oxidation in meat products because many further-processed meat products are cooked before distribution or consumption. Phenolic compounds have been considered as good chelators (Hider and others 2001) because the negatively charged phenoxide groups of deprotonated phenolic compounds chelate free ionic irons and stabilize the form of the free ionic irons. However, it is uncertain which compounds contributed to higher iron chelating capacity in RBE-HS and further study is needed.

\section{Effect on lipid oxidation in raw and cooked patties during storage}

The effect of purple rice bran extract on the development of lipid oxidation, expressed as TBARS values, in raw and cooked catfish patties during $12 \mathrm{~d}$ of storage at $4^{\circ} \mathrm{C}$ is shown in Figure $1 \mathrm{~A}$ and $1 \mathrm{~B}$.

Table 1-Various indexes for antioxidant activities of hexane-insoluble and hexane-soluble fractions from $100 \%$ methanol extract from purple rice bran (RBE-HI and RBE-HS, respectively) and rosemary extract (RE). ${ }^{A}$

\begin{tabular}{|c|c|c|c|c|c|c|c|}
\hline & $\begin{array}{c}\text { Total anthocyanin } \\
\text { content } \\
\text { ( } \mu \mathrm{g} \text { kuromanin } \\
\text { eqv./mg) }\end{array}$ & $\begin{array}{l}\text { Total tannin } \\
\text { content } \\
\text { ( } \mu \mathrm{g} \text { catechin } \\
\text { eqv./mg) }\end{array}$ & $\begin{array}{l}\text { Total flavonoid } \\
\text { content } \\
\text { ( } \mu \text { g catechin } \\
\text { eqv./mg) }\end{array}$ & $\begin{array}{c}\text { Total phenolics } \\
\text { content } \\
(\mu \mathrm{g} \text { gallic } \\
\text { acid eqv./mg) }\end{array}$ & $\begin{array}{c}\text { DPPH scavenging } \\
\text { capability } \\
\text { ( } \mu \mathrm{g} \text { Trolox } \\
\text { eqv./mg) }\end{array}$ & $\begin{array}{c}\text { ORAC value } \\
\text { ( } \mu \mathrm{g} \text { Trolox } \\
\text { eqv./mg) }\end{array}$ & $\begin{array}{c}\text { Iron chelating } \\
\text { capability } \\
\text { ( } \mu \text { g gallic } \\
\text { acid eqv./mg) }\end{array}$ \\
\hline RBE-HI & $90.05^{a}$ & $5.89^{a}$ & $50.96^{a}$ & $113.31^{a}$ & $169.95^{a}$ & $582.68^{a}$ & $28.89^{a}$ \\
\hline RBE-HS & $16.77^{b}$ & $0.57^{b}$ & $14.37^{b}$ & $9.49^{c}$ & $15.04^{c}$ & $322.14^{b}$ & $40.39^{b}$ \\
\hline $\mathrm{RE}$ & n.d. ${ }^{C}$ & n.d. ${ }^{B}$ & $2.55^{c}$ & $14.22^{\mathrm{b}}$ & $21.85^{b}$ & $158.88^{c}$ & n.d. ${ }^{B}$ \\
\hline SEM & 1.03 & 0.14 & 0.42 & 0.19 & 0.27 & 8.42 & 0.32 \\
\hline
\end{tabular}

${ }^{A}$ Means with different letters (a to $\mathrm{c}$ ) within the same column are significantly different $(P<0.05)$. SEM $=$ standard error of the mean. $n=3$. B Hydrophilic ORAC values were measured for RBE-HI, and lipophilic ORAC values were measured for RBE-HS and RE.

$\mathrm{C}_{\mathrm{n}}$.d. $=$ not detected, indicating that the values were below minimum in the standard curve.

$\mathrm{DPPH}=1,1$-diphenyl-2-picrylhydrazyl; ORAC = oxygen radical absorbance capacity.

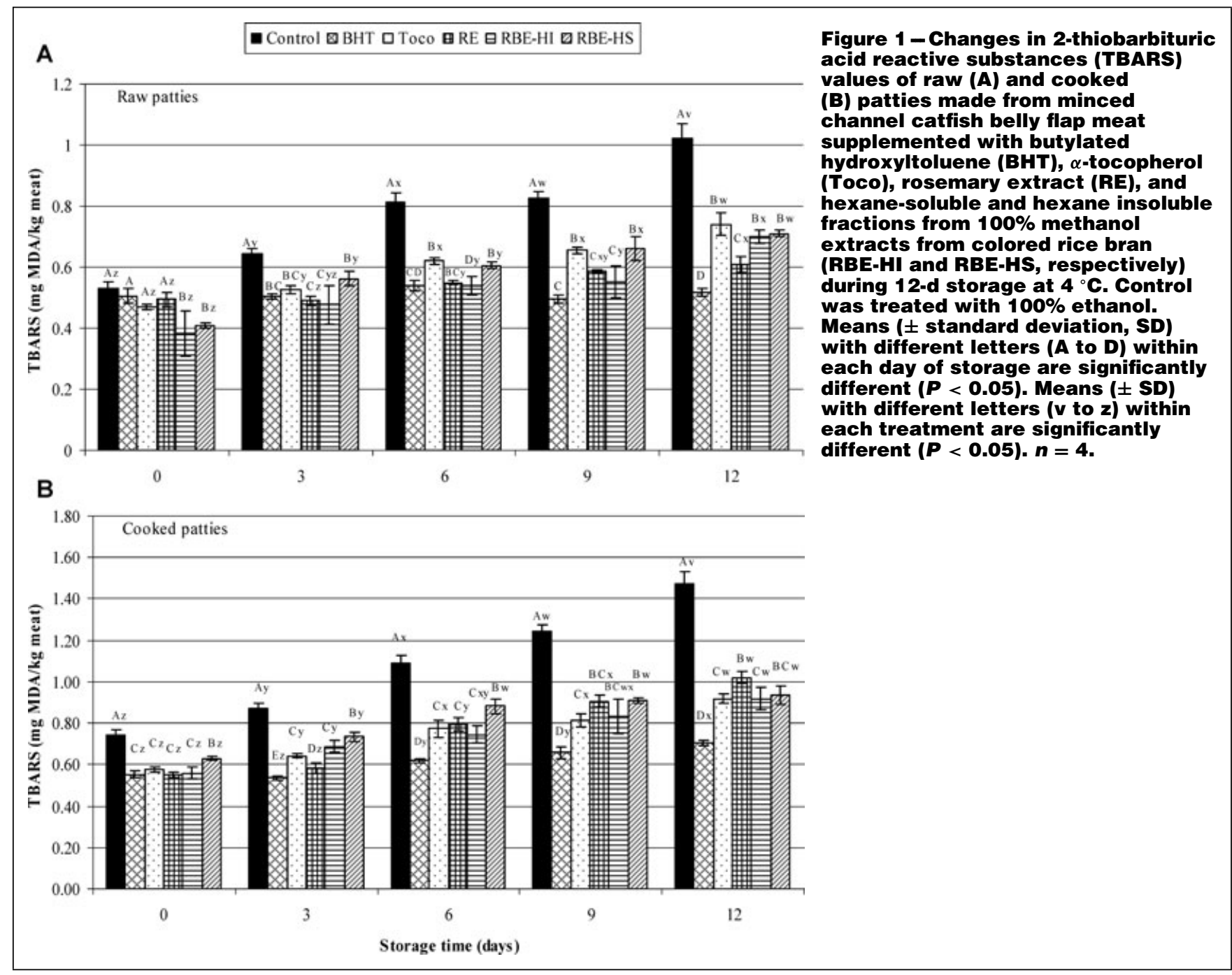


The initial (day 0) TBARS values for raw patties with RBE-HI and RBE-HS was significantly lower than those for control and patties with other treatments $(P<0.05)$ (Figure $1 \mathrm{~A})$. TBARS value of control sample increased significantly during storage, and at a much higher rate than in the antioxidant-treated patties $(P<0.05)$. The standard synthetic antioxidant, BHT, showed the strongest antioxidant activity in the raw patties during storage, inhibiting increases in the TBARS value. Increases in TBARS values of patties treated with natural antioxidants were observed throughout the storage period, but their rates of increase were significantly lower than those of the control $(P<0.05)$. The raw RE-treated patties showed the lowest TBARS values among natural antioxidant-treated patties after $12 \mathrm{~d}$ of storage. Antioxidant activity of RE was similar to BHT until day 6 , but gradually lost its antioxidant capacity thereafter. In the raw patties, antioxidant activity of RBE-HI was similar to that of BHT-treated patties until day 6 and to RE-treated patties until day 9 , after which its antioxidant activity decreased significantly $(P$ $<0.05$ ). At day 12, the TBARS value of raw RBE-HI-treated patties was the same as those of raw Toco- and RBE-HS-treated patties. In general, an antioxidant becomes an antioxidant radical after scavenging a free radical (Min and Ahn 2005). The antioxidant radical can be recovered by reducing agents such as ascorbic acid. Although the assay for total phenolics content is a measurement of reducing capacity of phenolic compounds in the extract for molybdenum (Huang and others 2005), it does not reflect their reducing power for antioxidant radicals in the food systems. Reducing ca-

Table 2-Changes in Commission Internationale de l'Eclairage (CIE) color attributes ( $L^{*}, a^{*}$, and $\left.b^{*}\right)$ and whiteness of raw patties made from channel catfish belly flap meat supplemented with butylated hydroxyltoluene (BHT), $\alpha$-tocopherol (Toco), rosemary extract (RE), and hexane-soluble and hexane insoluble fractions from $100 \%$ methanol extract from purple rice bran (RBEHI and RBE-HS, respectively) during 12-d storage.. ${ }^{A}$

\begin{tabular}{|c|c|c|c|c|c|c|c|}
\hline & Control & BHA & Toco & RE & RBE-HI & RBE-HS & SEM \\
\hline \multicolumn{8}{|l|}{$L^{*}$} \\
\hline $0 \mathrm{~d}$ & $79.18^{a}$ & $80.00^{a}$ & $80.11^{a}$ & $78.60^{\mathrm{a}}$ & $58.50^{c x}$ & $73.12^{b}$ & 0.818 \\
\hline $3 d$ & $80.54^{\mathrm{ab}}$ & $79.70^{\mathrm{b}}$ & $81.03^{a}$ & $80.33^{\mathrm{ab}}$ & $57.39^{d x}$ & $75.29^{c}$ & 0.26 \\
\hline $6 \mathrm{~d}$ & $80.25^{a}$ & $80.07^{a}$ & $80.30^{\mathrm{a}}$ & $80.92^{\mathrm{a}}$ & $55.67^{\text {cy }}$ & $74.13^{b}$ & 0.27 \\
\hline $9 d$ & $80.36^{a}$ & $80.11^{a}$ & $80.04^{a}$ & $79.39^{a}$ & $54.51^{\text {by }}$ & $73.96^{b}$ & 0.26 \\
\hline $12 d$ & $79.63^{a}$ & $79.47^{a}$ & $79.51^{a}$ & $79.36^{a}$ & $54.71^{\text {by }}$ & $73.07^{b}$ & \\
\hline SEM & & & & 0.591 & 0.287 & & \\
\hline \multicolumn{8}{|l|}{$a^{*}$} \\
\hline $0 \mathrm{~d}$ & $0.12^{\mathrm{a}}$ & $0.17^{a}$ & $0.33^{a}$ & $0.18^{a}$ & $-0.60^{b x}$ & $-0.85^{b w}$ & 0.0 \\
\hline $3 d$ & $0.29^{a}$ & $0.21^{a}$ & $0.32^{a}$ & $0.23^{a}$ & $-4.70^{c z}$ & $-1.76^{b x}$ & 0.03 \\
\hline $6 d$ & $0.21^{a}$ & $0.24^{a}$ & 0.22 & $0.30^{\mathrm{a}}$ & $-4.61^{c z}$ & $-2.11^{\text {by }}$ & 0.03 \\
\hline $9 d$ & $0.23^{a}$ & $0.05^{b}$ & $0.31^{a}$ & $0.23^{a}$ & $-4.62^{d z}$ & $-2.31^{\mathrm{cz}}$ & 0.03 \\
\hline $12 d$ & 0.3 & $0.05^{\mathrm{b}}$ & $0.28^{a}$ & $0.21^{\mathrm{a}}$ & $-4.09^{\mathrm{dy}}$ & $-2.31^{c z}$ & 0.03 \\
\hline SEM & 0.036 & 0.033 & 0.0 & 0.045 & 0.032 & & \\
\hline \multicolumn{8}{|l|}{$b^{*}$} \\
\hline $0 \mathrm{~d}$ & $11.79^{b}$ & $12.24^{b}$ & $12.13^{\mathrm{b}}$ & $12.14^{b}$ & $-1.81^{c x}$ & $15.13^{\mathrm{a}}$ & 0.3 \\
\hline $3 d$ & $12.02^{b}$ & $11.34^{\mathrm{b}}$ & $12.20^{\mathrm{b}}$ & $11.95^{\mathrm{b}}$ & $-4.75^{\text {cy }}$ & $15.33^{a}$ & 0.22 \\
\hline $6 \mathrm{~d}$ & $12.07^{b}$ & $12.02^{b}$ & $11.76^{b}$ & $12.47^{b}$ & $-5.06^{\mathrm{cyz}}$ & $14.67^{a}$ & 0.16 \\
\hline $9 \mathrm{~d}$ & $11.82^{c}$ & $11.91^{\mathrm{c}}$ & $12.24^{\mathrm{bc}}$ & $12.41^{\mathrm{b}}$ & $-5.12^{\mathrm{dz}}$ & & 0.10 \\
\hline $12 \mathrm{~d}$ & $12.25^{\mathrm{b}}$ & $12.28^{\mathrm{b}}$ & $12.39^{b}$ & $12.91^{\mathrm{b}}$ & $-4.74^{\text {cy }}$ & $14.99^{\mathrm{a}}$ & 0.2 \\
\hline SEM & 0.182 & 0.189 & 0.161 & 0.203 & 0.076 & 0.373 & \\
\hline \multicolumn{8}{|c|}{ Whiteness } \\
\hline $0 \mathrm{~d}$ & $76.05^{a}$ & $76.54^{a}$ & $76.69^{a}$ & $75.24^{a}$ & $58.45^{c x}$ & $68.99^{b}$ & 0.63 \\
\hline $3 d$ & $77.10^{\mathrm{a}}$ & $76.68^{a}$ & $77.44^{a}$ & $76.97^{a}$ & $56.87^{c y}$ & $70.86^{\mathrm{b}}$ & 0.2 \\
\hline $6 d$ & $76.84^{\mathrm{a}}$ & $76.71^{\mathrm{a}}$ & $77.05^{a}$ & $77.19^{a}$ & $55.15^{\mathrm{cz}}$ & $70.17^{b}$ & 0.27 \\
\hline $9 \mathrm{~d}$ & $77.06^{a}$ & $76.80^{\mathrm{a}}$ & $76.57^{a}$ & $75.93^{a}$ & $53.99^{c z}$ & $69.87^{b}$ & 0.2 \\
\hline $12 \mathrm{~d}$ & $76.19^{a}$ & $76.07^{a}$ & $76.05^{a}$ & $75.63^{a}$ & $54.28^{c z}$ & $69.08^{b}$ & 0.25 \\
\hline SEM & 0.105 & 0.266 & 0.220 & 0.504 & 0.289 & 0.543 & \\
\hline
\end{tabular}

${ }^{A}$ Means with different letters (a to $d$ ) within the same row are significantly different $(P<0.05)$. Means with different letters ( $w$ to $\mathrm{z}$ ) within the same column are significantly different $(P<0.05)$. SEM $=$ standard error of the mean. $n=4$ Control was treated with $100 \%$ ethanol. pacity of every phenolic compound can vary, depending on its own reducing potential, structure, and medium condition such as $\mathrm{pH}$, temperature, and so on. Therefore, we assume that RE has more phenolic compounds that can serve as reducing agents for antioxidant radicals in the particular condition of the patty to prolong its antioxidant activity compared to RBE-HI. Phenolic compounds identified in RE are carnosol, carnosic acid, rosemanol, rosemadial, epirosemanol, rosemadiphenol, rosemarinic acid, and so on (Bozin and others 2007). No differences in antioxidant activities between $\alpha$-tocopherol (Toco) and RBE-HS-treated patties were observed during storage, and their TBARS values were significantly higher than those of other treatments $(P<0.05)$. We assume that the major components of RBE-HS ( $\gamma$-oryzanols, tocopherols, and tocotrienols) have similar structures and modes of antioxidant action for preventing lipid oxidation in meat products to $\alpha$-tocopherol, resulting in the similar TBARS values in the patties.

In cooked patties, the initial (day 0) TBARS value of the control was significantly higher than that of the antioxidant-treated patties $(P<0.05)$ (Figure 1B). Heating accelerates lipid oxidation and production of volatiles in meat (Beltran and others 2003) by disrupting muscle cell structure, inactivating antioxidant enzymes and other antioxidant compounds, and releasing iron from heme pigments (Kanner 1994). High temperature causes reduction of activation energy for lipid oxidation and decomposes preformed hydroperoxides to free radicals, which stimulates autoxidation processes and
Table 3-Changes in Commission Internationale de l'Eclairage (CIE) color values ( $L^{*}, a^{*}$, and $\left.b^{*}\right)$ and whiteness of cooked patties made from channel catfish belly flap meat supplemented with butylated hydroxyltoluene (BHT), $\alpha$-tocopherol (Toco), rosemary extract (RE), and hexane-soluble and hexane insoluble fractions from $100 \%$ methanol extract from purple rice bran (RBEHI and RBE-HS, respectively) during 12-d storage. ${ }^{A}$

\begin{tabular}{|c|c|c|c|c|c|c|c|}
\hline & Control & BHA & Toco & RE & RBE-HI & RBE-HS & SEM \\
\hline \multicolumn{8}{|l|}{$L^{*}$} \\
\hline $0 \mathrm{~d}$ & $80.30^{a}$ & $80.10^{a}$ & $78.50^{\mathrm{a}}$ & $79.23^{a}$ & $48.45^{c}$ & $70.85^{\text {by }}$ & 0.600 \\
\hline $3 d$ & & & & & & & 0.402 \\
\hline $6 \mathrm{~d}$ & 79.4 & 79.8 & 80.7 & 79.7 & $50.12^{c}$ & $71.31^{b x y}$ & 0.757 \\
\hline $9 d$ & & & $78.65^{b}$ & $79.41^{\mathrm{ab}}$ & $47.98^{d}$ & & 0.321 \\
\hline $12 \mathrm{~d}$ & & & a & 80. & $48.77^{c}$ & & 0.485 \\
\hline SEM & & & & & & & \\
\hline \multicolumn{8}{|l|}{$a^{*}$} \\
\hline $0 \mathrm{~d}$ & & $0.01^{\mathrm{bw}}$ & $-0.11^{\mathrm{bw}}$ & $0.02^{\mathrm{bw}}$ & $1.53^{\mathrm{ax}}$ & $0.02^{b x}$ & 0.057 \\
\hline $3 d$ & & $-0.48^{b x}$ & $-0.60^{\mathrm{bcx}}$ & $-0.51^{b x}$ & $0.41^{\text {ay }}$ & & 0.058 \\
\hline $6 \mathrm{~d}$ & -1.02 & $-0.76^{\text {by }}$ & & $-0.97^{\text {by }}$ & $-0.02^{\mathrm{ay}}$ & & 0.075 \\
\hline $9 d$ & -1 & -1 & & $-1.15^{\mathrm{bz}}$ & $0.47^{\text {ay }}$ & & 0.061 \\
\hline $12 d$ & -1.2 & -1.0 & -1. & $-1.26^{\mathrm{cz}}$ & $0.01^{\text {ay }}$ & & 0.096 \\
\hline SEM & & & & & 0.140 & & \\
\hline \multicolumn{8}{|l|}{$b^{*}$} \\
\hline $0 \mathrm{~d}$ & & & & & & & 0.218 \\
\hline $3 d$ & & & & 15. & -0.1 & & 0.161 \\
\hline $6 \mathrm{~d}$ & & & & & & & 0.219 \\
\hline $9 \mathrm{~d}$ & & & & & & & 0.178 \\
\hline $12 d$ & 15.2 & 14.7 & $15.08^{\mathrm{ab}}$ & $15.22^{\mathrm{ab}}$ & $-0.56^{\text {cy }}$ & & 0.264 \\
\hline SEM & & & 241 & 0.240 & 0.214 & 0.202 & \\
\hline \multicolumn{8}{|c|}{ Whiteness } \\
\hline $0 \mathrm{~d}$ & $75.13^{\mathrm{a}}$ & & & & & & 0.572 \\
\hline $3 d$ & & $75.27^{a}$ & $74.76^{a}$ & 74.6 & & & 0.360 \\
\hline $6 \mathrm{~d}$ & $74.54^{\mathrm{a}}$ & $74.66^{a}$ & & 74. & $50.12^{c}$ & & 0.734 \\
\hline $9 \mathrm{~d}$ & & & & & & & 0.31 \\
\hline $12 \mathrm{~d}$ & 74.9 & 75.6 & 74.8 & $74.84^{\mathrm{a}}$ & $48.76^{c}$ & $68.10^{\mathrm{bx}}$ & 0.481 \\
\hline SEM & 0.337 & 0.401 & 0.562 & 0.499 & 0.778 & 0.381 & \\
\hline
\end{tabular}

A Means with different letters (a to d) within the same row are significantly different $(P<0.05)$. Means with different letters ( $w$ to $z$ ) within the same column are significantly different $(P<0.05)$. SEM $=$ standard error of the mean. $n=4$. Control was treated with $100 \%$ ethanol. 
off-flavor development (Min and Ahn 2005). In all cooked patties, TBARS values increased during storage, but the addition of antioxidants slowed the rate of increase. After $12 \mathrm{~d}$ of storage, BHTtreated patties had the lowest TBARS value, whereas RE-treated patties had the highest among antioxidant-treated patties. On day 12, TBARS values of Toco-, RBE-HI-, and RBE-HS-treated patties did not differ significantly $(P>0.05)$. The pattern of increases in TBARS values during storage differed among cooked patties treated with natural antioxidants. The TBARS value of RE-treated patties increased significantly after day 3 , whereas those of RBE-HS-treated patties increased significantly only until day $6(P<0.05)$. During storage, TBARS values of RBE-HI- and Toco-treated patties increased gradually. In addition, the change in TBARS value during storage within treatment differed between raw and cooked patties. We attribute these differences to different modes of antioxidant action by the natural extracts given their different profiles of phenolic compounds. Heating also can change these profiles in natural extracts by inactivating heat-labile phenolic compounds. However, the antioxidant mechanisms of the components in natural extracts in real food systems have not been studied.

Antioxidant activity of RBE-HI in raw and cooked patties after $12 \mathrm{~d}$ of storage did not differ from those of RBE-HS and were even lower than those of RE in raw patties (Figure 1), whereas its antioxidant indexes, such as DPPH scavenging capability and ORAC values (Table 1), were much greater than those of RBE-HS and RE. Frankel and Meyer (2000) suggested limitation to the use of one-dimensional methods to predict the effectiveness of natural extracts as antioxidants in complex food systems. They indicated that test methods such as the DPPH scavenging capability and the ORAC method, which measures the free radical trapping ability of antioxidants, do not consider the complexity of antioxidant action. In real food systems, like meat products, the antioxidant action becomes more complicated and the various mechanisms, including free radical chain breaking, oxygen scavenging, metal chelation, and inhibition of oxidative enzymes, are effective. In addition, Porter (1993) suggested the paradoxical behavior of antioxidants in

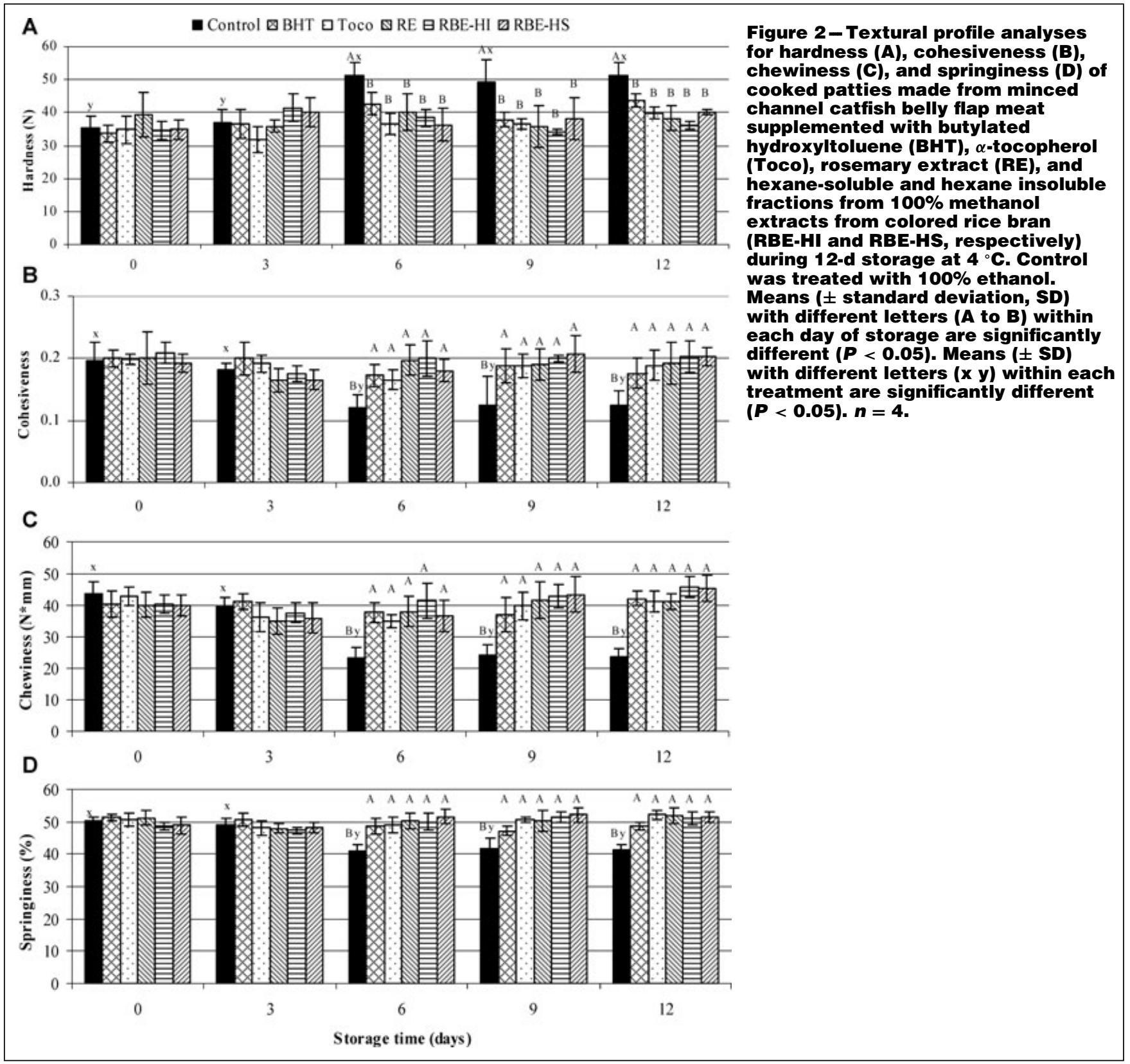


food systems on the basis of phenomenological observation. He indicated that hydrophilic antioxidants are more active in bulk oil systems but lipophilic antioxidants are more active in lipid suspended in aqueous systems like an oil-in-water emulsion. Meat products, including the catfish patties in this study, are similar to lipid suspended in aqueous systems. Therefore, the higher iron chelating capability (Table 1) and hydrophobicity of RBE-HS may account for its higher effectiveness as an antioxidant in the patties, compared to RBE-HI.

\section{Effect on changes of color and textural properties in the catfish patties}

The addition of BHT, Toco, and RE did not change any color attributes $\left(L^{*}, a^{*}, b^{*}\right.$, and whiteness) in the raw patties, compared to the control (Table 2). However, RBE-HI- and RBE-HS-treated patties had significantly lower $L^{*}, a^{*}$, and whiteness values compared to the control and Toco- and RE-treated patties $(P<0.05)$, and the $b^{*}$ value of RBE-HI-treated patties was significantly lower $(P<0.05)$. These changes were attributed to the presence of anthocyanins, natural colorants, responsible for the dark purple color of the pigmented rice bran. The different concentration of total anthocyanins of RBE-HI- and RBE-HS-treated patties (Table 1) likely caused the difference in patty color attributes between these 2 treatments. The presence of carotenoids, natural lipid-soluble colorants, identified in rice bran oil (Stoggl and others 2005) likely resulted in the increased yellowness ( $b^{*}$ value) and decreased redness ( $a^{*}$ value) in the RBE-HS raw patties. In addition, all color attributes in RBE-HI-treated patties changed significantly during
$12 \mathrm{~d}$ of storage $(P<0.05)$ due probably to a loss of monomeric anthocyanins and an increase of polymeric color, resulting from the polymerization of anthocyanins during storage (Hager and others 2008). Meanwhile, cooking increased $b^{*}$ values, but decreased whiteness of all patties because of relative increases in pigment concentration by loss of water during cooking (Table 3). In addition, heating may increase anthocyanin polymerization (Hager and others 2008), resulting in changes of color attributes in cooked RBEHI-treated patties

Figure 2 shows the effect of antioxidants on changes in textural properties (hardness, cohesiveness, chewiness, and springiness) of cooked catfish patties during $12 \mathrm{~d}$ of storage. Initial (day 0) values of all textural parameters in all treatments did not differ. However, all textural parameters of the control patties changed during storage. Hardness of control patties increased significantly $(P<0.05)$, whereas cohesiveness, chewiness, and springiness decreased significantly after day $4(P<0.05)$. On the other hand, textural parameters of antioxidant-treated patties remained unchanged during storage and no differences were observed among treatments during storage. Free radicals generated in the patties can cause not only the development of lipid oxidation but also protein oxidation, resulting in denaturation of protein molecules (Min and Ahn 2005). In addition, the lipid oxidation secondary products can also cause protein denaturation, which deteriorates texture properties of meat products (Kanner 1994). Myofibrillar proteins play crucial roles in functional properties, such as water holding properties and textural properties, in meat products. Oxidative damage of proteins may cause loss of protein solubility, aggregation, and complex

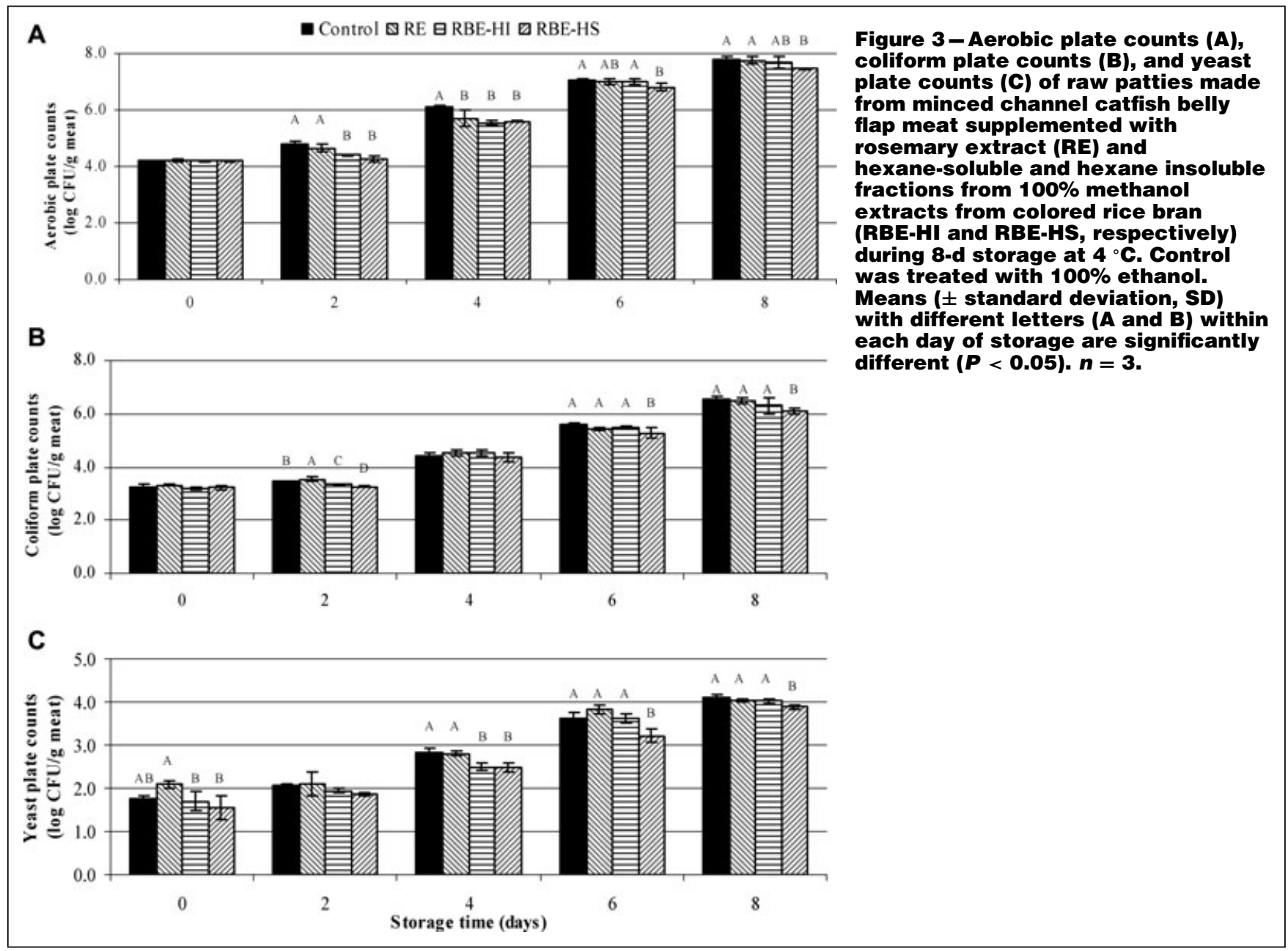


formation, and consequently loss of protein network (Karel and others 1975, Estévez and others 2006). These changes can result in reduced spaces between the protein molecules in the patties, leading to greater loss of moisture during storage and consequently a harder texture in meat products. In addition, broken protein networks can cause loss of textural properties such as cohesiveness, chewiness, and springiness. Therefore, we assume that inclusion of antioxidants may prevent the development of protein oxidation in and maintain the textural properties of the patties during storage.

\section{Effect on microbial growth in raw catfish patties}

The initial (day 0) aerobic plate counts (APC), coliform plate counts (CPC), and yeast plate counts (YPC) did not differ between the control and natural extract-treated patties and the APC, CPC, and YPC increased significantly in all the patties during $8 \mathrm{~d}$ of storage $(P<0.05)$ (Figure 3$)$. Microbial growth in the patties during storage was not inhibited by RE and RBE-HI. Several studies have shown the antimicrobial effect of RE on foodborne pathogens such as E. coli (Del Campo and others 2000; Fernández-López and others 2005; Bozin and others 2007). Del Campo and others (2000) indicated that compounds responsible for antimicrobial activities in RE are probably lipid-soluble phenolic diterpenes which are the major antioxidants of RE. This suggestion explains the absence of antimicrobial activities in RBE-HI. However, these researchers used in vitro microbiological test such as agar diffusion method and used undiluted natural extracts in their studies. The doses of natural extracts in their studies were much higher than those used in this study. In addition, it was suggested that the physical interaction between antimicrobial agents and "real" food matrix may interfere their antimicrobial activity in food systems (Fernández-López and others 2005). Microbial growth was inhibited in the RBE-HS-treated patties after $12 \mathrm{~d}$ of storage $(P<0.05$; Figure $3 \mathrm{~A}, 3 \mathrm{~B}$, and $3 \mathrm{C})$. Lipidsoluble phenolic compounds, such as $\gamma$-oryzanol, in the RBE-HS may account for its antimicrobial activities. However, low dose and physical interaction with the matrix of the patties may restrict the antimicrobial activities of RBE-HS in the patties during storage.

\section{Conclusions}

$\mathrm{R}$ BE-HI showed higher total phenolics content, DPPH scavenging capability, and ORAC value, but lower iron chelating capability, compared to RBE-HS. On the other hand, both fractions showed similar antioxidant activity in raw and cooked catfish patties and maintained better textural properties of cooked patties during $12 \mathrm{~d}$ of storage, compared to the control. Only RBE-HS presented antimicrobial activities in raw patties during storage, but its effect was marginal due to low dose and interaction with the matrix of the patties. However, inclusion of RBE-HI and RBE-HS significantly changed color attributes in raw and cooked catfish patties. We suggest that purple rice bran extract is a good candidate as a natural preservative for extending shelf life and preventing deterioration of meat product quality. Furthermore, purple rice bran extract can add health benefits to meat products. Color change of the patty, however, should be considered and the mechanism of this color change requires further research.

\section{Acknowledgment}

We thank Texas Rice Improvement Association for providing the IAC600 as a gift for this research.

\section{References}

Abdel-Aal ES, Hucl P. 1999. A rapid method for quantifying total anthocyanins in blue aleurone and purple pericarp wheats. Cereal Chem 76:350-4.
Ahn DU, Kim SM. 1998. Prooxidant effects of ferrous iron, hemoglobin, and ferritin in oil emulsion and cooked meat homogenates are different from those in raw-meat homogenates. Poultry Sci 77:348-55.

Ahn J, Grün IU, Mustapha A. 2007. Effects of plant extracts on microbial growth, color change, and lipid oxidation in cooked beef. Food Microbiol 24:7-14.

Ames BN, Gold LS, Willet WC. 1995. The causes and prevention of cancer. Proc Natl Acad Sci USA 92:5258-65.

[AOAC] Association of Official Analytical Chemists. 2005. Official methods of analysis of AOAC International. 18th ed. Gaithersburg, Mass.: AOAC International.

Balasundram N, Sundram K, Samman S. 2006. Phenolic compounds in plants and agri-industrial by-products: antioxidant activity, occurrence, and potential use. Food Chem 99:191-203.

Beltran E, Pla R, Yuste J, Mor-Mur M. 2003. Lipid oxidation of pressurized and cooked chicken: role of sodium chloride and mechanical processing on TBARS and hexanal values. Meat Sci 64:19-25.

Block G, Patterson B, Suber A. 1992. Fruits, vegetables and cancer prevention: a review of the epidemiological evidence. Nutr Cancer 18:1-29.

Bourne M. 2002. Food texture and viscosity. 2nd ed. New York: Academic Press. p 1826.

Bozin B, Mimica-Dukic NM, Samojlik I, Jovin E. 2007. Antimicrobial and antioxidant properties of rosemary and sage (Rosmarinus officinalis L. and Salvia officinalis L. Lamiaceae) essential oils. J Agric Food Chem 55:7879-85.

Bramley PM, Elmadfa I, Kafatos A, Kelly FJ, Manios Y, Roxborough HE, Schuch W, Sheehy PJA, Wagner KH. 2000. Review: vitamin E. J Sci Food Agric 80:913-38.

Carter P. 1971. Spectrophotometric determination of serum iron at the submicrogram level with a new reagent (ferrozine). Anal Biochem 40:450-8.

Cicero AFG, Gaddi A. 2001. Rice bran oil and $\gamma$-oryzanol in the treatment of hyperlipoproteinemias and other conditions. Phytother Res 15:277-89.

Del Campo J, Amiot MJ, Nguyen-The C. 2000. Antimicrobial effect of rosemary extracts. J Food Prot 63:1359-68.

Elgayyar M, Draughon FA, Golden DA, Mount JR. 2001. Antimicrobial activity of essential oils from plants against selected pathogenic and saprophytic microorganisms. J Food Prot 64:1019-24.

Estévez M, Ventanas S, Ramón C. 2006. Protein oxidation in frankfurters with increasing levels of added rosemary essential oil: effect on color and texture deterioration. J Food Sci 70:C427-32.

Fernández-López J, Zhi N, Aleson-Carbonell L, Pérez-Alvarez JA, Kuri V. 2005. Antioxidant and antibacterial activities of natural extracts: application in beef meatballs Meat Sci 69:371-80.

Frankel EN, Meyer AS. 2000. The problems of using one-dimensional methods to evaluate multifunctional food and biological antioxidants. J Sci Food Agric 80:192541

Gerhardt AL, Gallo NB. 1998. Full-fat rice bran and oat bran similarly reduce hypercholesterolemia in humans. J Nutr 128:865-9.

Goffman FD, Bergman CJ. 2004. Rice kernel phenolic content and its relationship with antiradical efficiency. J Sci Food Agric 84:1235-40.

Hager TJ, Howard LR, Prior RL. 2008. Processing and storage effects on monomeric anthocyanins, percent polymeric color, and antioxidant capacity of processed blackberry products. J Agric Food Chem 56:689-95.

Halliwell B, Gutteridge JMC. 1999. Free radicals in biology and medicine. 3rd ed. New York: Oxford Univ Press Inc.

Hammer KA, Carson CF, Riley TV. 1999. Antimicrobial activity of essential oils and other plant extracts. J Appl Microbiol 86:985-90.

Han J, Rhee KS. 2005. Antioxidant properties of selected oriental non-culinary/ nutraceutical herb extracts as evaluated in raw and cooked meat. Meat Sci 70:2533.

Hider RC, Liu ZD, Khodr HH. 2001. Metal chelation of polyphenols. Methods Enzymol 335:190-203.

Hu C, Zawistowski J, Ling W, Kitts DD. 2003. Black rice (Oryza sativa L. indica) pigmented fraction suppresses both reactive oxygen species and nitric oxide in chem ical and biological model systems. J Agric Food Chem 51:5271-7.

Huang D, Ou B, Hampsch-Woodill M, Flanagan JA, Prior RL. 2002a. High throughput assay of oxygen radical absorbance capacity (ORAC) using a multichannel liquid handling system coupled with a microplate fluorescence reader in 96-well format. J Agric Food Chem 50:4037-44.

Huang D, Ou B, Hampsch-Woodill M, Flanagan JA, Deemer EK. 2002b. Development and validation of oxygen radical absorbance capacity assay for lipophilic antioxidants using randomly methylated $\beta$-cyclodextrin as the solubility enhancer. J Agric Food Chem 50:1815-21.

Huang D, Ou B, Prior RL. 2005. The chemistry behind antioxidant capacity assays. J Agric Food Chem 53:1841-56.

Jacobs DR, Slavin J, Marquart L. 1995. Whole grain intake and cancer: A review of literature. Nutr Cancer 22:221-9.

Jariwalla RJ. 2001. Rice-bran products: Phytonutrients with potential applications in preventive and clinical medicine. Drugs Exp Clin Res 27:17-26.

Kanner J. 1994. Oxidative processes in meat and meat products: quality implications. Meat Sci 36:169-89.

Kar P, Laight D, Shaw KM, Cummings MH. 2006. Flavonoid-rich grapeseed extracts: a new approach in high cardiovascular risk patients? Int J Clin Prac 60:1484-92.

Karel M, Schaich K, Roy RB. 1975. Interaction of peroxidizing methyl linoleate with some proteins and amino acids. J Agric Food Chem 23:159-63.

Kim JS, Godber JS. 2001. Oxidative stability and vitamin E levels increased in restruc tured beef roast with added rice bran oil. J Food Qual 24:17-26.

Kuehl RO. 2000. Design of experiments: statistical principles of research design and analysis. 2nd ed. New York: Duxbury Press. p 107-10.

Ling WH, Cheng QX, Ma J, Wang T. 2001. Red and black rice decrease atherosclerotic plaque formation and antioxidant status in rabbits. J Nutr 131:1421-6.

Min B, Ahn DU. 2005. Mechanism of lipid oxidation in meat and meat products: a review. Food Sci Biotechnol 14:152-63.

Min B, Ahn DU. 2009. Factors in various fractions of meat homogenates that affect the oxidative stability of raw chicken breast and beef loin. J Food Sci 74:C41-8. 
Min B, Green BW. 2008. Use of microbial transglutaminase and non-meat proteins to improve functional properties of low $\mathrm{NaCl}$, phosphate-free patties made from channel catfish (Ictalurus punctatus) belly flap meat. Food Sci 73:E218-26.

Min B, Nam KC, Cordray J, Ahn DU. 2008. Endogenous factors affecting oxidative stability of beef loin, pork loin, and chicken breast and thigh meats. J Food Sci 73:C439-46.

Morrissey PA, Sheehy PJA, Galvin K, Kerry JP, Buckley DJ. 1998. Lipid stability in meat and meat products. Meat Sci 49:S73-86.

Nam SH, Choi SP, Kang MY, Koh HJ, Kozukue N, Friedman M. 2006. Antioxidative activities of bran from twenty one pigmented rice cultivars. Food Chem 94:613-20.

Nanua JN, McGregor JU, Godber JS. 2000. Influence of high oryzanol rice bran oil on the oxidative stability of whole milk powder. J Dairy Sci 83:2426-31.

Ness AR, Powles JW. 1997. Fruit and vegetables, and cardiovascular disease: a review. Int J Epidemiol 26:1-13.

Nissen LR, Byrne DV, Bertelsen G, Skibsted LH. 2004. The antioxidative activity of plant extracts in cooked pork patties as evaluated by descriptive sensory profiling and chemical analysis. Meat Sci 68:485-95.

Oki T, Masuda M, Kobayashi M, Nishiba Y, Furuta S, Suda I. 2002. Polymeric procyanidins as radical-scavenging components in red-hulled rice. J Agric Food Chem 50:7524-9.

Park JW. 2000. Ingredient technology and formulation development. In: Park JW, editor. Surimi and surimi seafood. New York: Marcel Dekker. p 343-91.

Philpott M, Gould KS, Lim C, Ferguson LR. 2006. In situ and in vitro antioxidant activity of sweetpotato anthocyanins. J Agric Food Chem 54:1710-5.

Porter WL. 1993. Paradoxical behavior of antioxidants in food and biological systems. Toxicol Ind Health 9:93-122.

Quereshi AA, Bradlow BA, Salser, WA, Brace LD. 1997. Novel tocotrienols of rice bran modulate cardiovascular disease risk parameters of hypocholesterolemic humans. J Nutr Biochem 8:290-8.
Rohrer CA, Siebenmorgen TJ. 2004. Nutraceutical concentrations within the bran of various rice kernel thickness fractions. Biosyst Eng 88:453-60.

Rojas MC, Brewer MS. 2007. Effect of natural antioxidants on oxidative stability of cooked, refrigerated beef and pork. J Food Sci 72:S282-8.

Satue-Gracia M, Heinonen IM, Frankel EN. 1997. Anthocyanins as antioxidants on human low-density lipoprotein and lecithin liposome systems. J Agric Food Chem 45:3362-7.

Sebranek JG, Sewalt VJH, Robbins KL, Houser TA. 2005. Comparison of a natural rosemary extract and BHA/BHT for relative antioxidant effectiveness in pork sausage. Meat Sci 69:289-96.

Shahidi F, Wanasundara PKJPD. 1992. Phenolic antioxidants. Crit Rev Food Sci Nutr 32:67-103.

Stoggl W, Huck C, Wongyai S, Scherz H, Bonn G. 2005. Simultaneous determination of carotenoids, tocopherols, and $\gamma$-oryzanol in crude rice bran oil by liquid chromatography coupled to diode array and mass spectrometric detection employing silica C30 stationary phases. J Sep Sci 28:1712-8.

Sun B, Ricardo-da-Silva JM, Spranger, I. 1998. Critical factors of vanillin assay for catechins and proanthocyanidins. J Agric Food Chem 46:4267-74.

Wijeratne SSK, Cuppett SL. 2007. Potential of rosemary (Rosemarinus officinalis L.) diterpenes in preventing lipid hydroperoxide-mediated oxidative stress in caco-2 cells. J Agric Food Chem 55:1193-9.

Wu X, Beecher GR, Holden JM, Haytowitz DB, Gebhardt SE, Prior RL. 2004. Lipophilic and hydrophilic antioxidant capacities of common foods in the United States. J Agric Food Chem 52:4016-37.

Zhishen J, Mengcheng T, Jianming W. 1999. The determination of flavonoid contents in mulberry and their scavenging effects on superoxide radicals. Food Chem 64:555-9. 